\title{
A mediação das narrativas no trabalho reconstrutivo de uma história de vida: o que os diários de classe contam
}

\section{Resumo}

Este artigo apresenta uma análise interpretativa dos meus diários de classe dos cinco primeiros anos de docência como professora de música em classes de Educação Infantil, no período de 1969 a 1973. Minha história de vida, reconfigurada por meio das narrativas que os registros e as memórias suscitam, tem por objetivo apreender 0 sentido mais profundo dos acontecimentos que vivi e a natureza daquilo que me constitui. Trata-se de uma interpretação de corte hermenêutico que encontra em Ricoeur (1991) a principal referência. A triangulação que insere minha história no cenário sociocultural segue os aportes de Ferrarotti (2014). O esforço reflexivo que busca um sentido de totalidade em minha breve história de vida revela, ao mesmo tempo, mudanças e permanências no processo que expressa a minha identidade narrativa.

Palavras-chave: História de Vida. Diário de Classe. Música na Educação Infantil.

\section{Leda de Albuquerque Maffioletti}

Universidade Federal do Rio Grande do Sul - UFRGS - Porto

Alegre/RS - Brasil leda.maffioletti@gmail.com

\section{Para citar este artigo:}

MAFFIOLETTI, Leda de Albuquerque. A mediação das narrativas no trabalho reconstrutivo de uma história de vida: o que os diários de classe contam. Revista Linhas. Florianópolis, v. 20, n. 42, p. 125-152, jan./dez. 2019 . 


\title{
Mediation of narratives in the reconstruction work of a life history: what class diaries tell
}

\begin{abstract}
This article presents an interpretive analysis of class diaries from my first five years as a music teacher in early childhood education from 1969 to 1973. My life history, reconfigured through the narratives triggered by records and memories, is told in order to grasp the deepest meaning of the events I have experienced and the nature of what I have come to be. It is a hermeneutical interpretation that finds its main reference in Ricoeur (1991). The triangulation that places my history in the sociocultural scene follows Ferrarotti's (2014) contributions. The reflexive effort that seeks a sense of totality in my brief life history reveals both changes and permanences in the process that expresses my narrative identity.
\end{abstract}

Keywords: Life History. Class Diary. Music in Children's Education 
Procuro-me no passado e 'outrem me vejo'; não encontro a que fui, encontro alguém que a que sou vai reconstruindo, com as marcas do presente. $\mathrm{Na}$ lembrança, o passado se torna presente e se transfigura, contaminado pelo aqui e o agora.

(Magda Soares, 2001)

\section{Introdução}

A pluralidade das visões que constituem a história da Educação Musical no Brasil pode ser conhecida a partir da história das instituições que se dedicaram ao ensino de música nos diferentes níveis, ou a partir dos movimentos pedagógicos que influenciaram o ensino de música, entre outras dimensões do campo musical, conforme assinala Souza (2014). O interesse pelas práticas específicas tem crescido entre os pesquisadores das áreas de Ciências Sociais, que procuram no elemento particular outros caminhos para atingir um conhecimento mais geral (PINEAU; LE GRAND, 2012). Para desvendar o geral a partir do particular, o universal através do singular, o objetivo com base no subjetivo, precisamos enfrentar o desafio de atribuir à subjetividade o valor de conhecimento. Com base em minhas experiências, compreendo que

Não se trata simplesmente de admitir que há outras formas de produzir conhecimento, mas entender que a adoção de uma perspectiva de pesquisa significa aceitar o paradigma que lhe dá sustentação, com repercussões no modo de compreender os acontecimentos do cotidiano, visão de ciência e de mundo. (MAFFIOLETTI, 2018, p. 203-204)

No campo da Educação Musical, as pesquisas que valorizam a expressão da temporalidade pessoal vivida pelos professores de música já estão presentes no cenário brasileiro pelo menos desde 1998. Por exemplo, Joly (1998) analisa as contribuições de uma professora de música como elemento formador de novos educadores musicais. O mesmo interesse pelas narrativas de professores de música pode ser constatado em livros organizados por Louro; Teixeira; Rapôso (2014) e Bellochio (2017). O interesse pelas histórias de vida ou de episódios de vida envolvendo a música pode ser encontrado nas pesquisa de Louro (2004) Torres (2008), Lima (2013), Dourado (2013), Alves (2014) Gaulke (2017), Weber (2014) Dallabrida (2015), Almeida (2016), Vieira (2017), Maffioletti (2017), Delmary (2017), Souza (2018), entre outros. 
As narrativas de histórias de vida revelam a natureza relacional de um pessoa com a sua vida. Os pequenos grupos sociais, como a família, os vizinhos, a escola, os colegas de trabalho e de faculdade, são oportunidades de desestruturação-re-estruturação psicológica e social que se incorporam ao nosso modo de ser. Ao invés de ser espelho da sociedade, cada um de nós atua como mediador ativo que, ao se apropriar, filtra e retraduz, projetando a dimensão social na direção de sua subjetividade (FERRAROTTI, 2014). As narrativas que produzimos a partir dessas vozes plurais não formam identidades sociais ou culturais, mas identidade narrativa (DELORY-MOMBERGER, 2018), que compreende a noção de identidade ligada à subjetividade e à permanência no tempo, que tem na temporalidade o elemento constitutivo de si mesmo (RICOEUR, 1991).

No campo da pesquisa (auto)biográfica", a noção de "biografia" não significa a realidade dos fatos vividos, mas as representações e discursos que construímos para tornar esses fatos inteligíveis. Assim compreendida, a biografia não tem outro campo de validade senão aquele onde ela produz a história de si (DELORY-MOMBERGER, 2018).

O objetivo desta investigação é fazer da minha vida uma pequena história, para ter acesso à construção dos sentidos que demarcaram as experiências que vivi num determinado período de tempo. O processo é mediado pelas narrativas suscitadas pela leitura dos diários de classe produzidos nos primeiros anos de docência. Por seu valor afetivo e histórico ligado ao ponto de partida de uma trajetória que durou 48 anos, acreditei ser possível deixar-me guiar pelas memórias que certamente os diários me trariam. Quero apreender os acontecimentos mais significativos, em câmara lenta, deixando-me afetar pelo passado, para conhecer da melhor maneira possível a natureza daquilo que me constitui.

\section{Situando a investigação}

Os diários de classe do professor, assim como outros cadernos e documentos produzidos no contexto escolar, guardam recordações consideradas verdadeiras “memórias de papel”, que ajudam o "reconhecimento de diferentes práticas, costumes, rituais, ações e sociabilidades" vividas no contexto educacional (MIGNOT; CUNHA, 2006,

\footnotetext{
${ }^{1} \mathrm{O}$ termo (auto)biográfico inclui parênteses para chamar a atenção sobre dois tipos de fontes nas pesquisas educacionais: as biografias e autobiografias (PASSEGGI, 2010, p. 108).
} 
42). O campo e o objeto de minha investigação implicam radicalmente a minha pessoa, o que afasta a possibilidade da produção de um conhecimento objetivo - nem seria essa a minha intenção. Para não trair as características de historicidade e subjetividade próprias de uma história de vida, abandono a lógica formal, tão bem aceita pela academia, para interpretar um fragmento da história social a partir da subjetividade presente em minha história pessoal.

Os diários de classe registram minhas atividades de professora de música desenvolvidas no Instituto Educacional João XXIII - uma escola comunitária da rede privada, criada em 1968 por uma equipe de professores sob a coordenação da professora Zilah Mattos Totta - educadora de destaque no estado do Rio Grande do Sul -, “defensora da educação libertadora e demitida do cargo de secretária de Educação porque afirmava não tolerar interferências retrógadas de superiores" impostas pelo Golpe Militar.

A proposta curricular apoiava-se nas teorias de Jean Piaget, Paulo Freire, Carl Rogers e Hilda Taba, motivo por que os anos escolares eram concebidos como fases de desenvolvimento, sendo cada etapa formada por dois níveis de escolaridade. Conservando a nomenclatura daquele tempo, seria assim:

Etapa I: Educação Infantil, fases 1 e 2, formada pelas turmas G2 e G3 e pelo nível A.

Etapa II: primeira fase, formada pelo nível B e segunda fase pelo $1^{\circ}$ ano.

Etapa III: fase 1 (correspondente ao $2^{\circ}$ ano, fase 2 (correspondente ao $3^{\circ}$ ano).

Etapa IV: fase 1 (correspondente ao $4^{\circ}$ ano), fase 2 (correspondente ao $5^{\circ}$ ano).

Etapa VI: corresponde à fase final do primeiro grau, correspondente aos $6^{\circ}, 7^{\circ}$ e $8^{\circ}$ anos.

As reuniões gerais envolvendo todos os professores das etapas aconteciam uma vez por semana, fora do horário escolar, sob a coordenação das diretoras de etapas e coordenadora pedagógica. Cada etapa comportava pelo menos dois professores de música. A partir da $3^{\text {a }}$ etapa, além das aulas de música, as crianças frequentavam aulas de flauta doce e aulas de artes. Formávamos uma grande equipe (Música e Artes) que integrava o Departamento Integrado de Educação Artística e Cultural - DIAC coordenado pela professora Dra. Leda Osório Mársico (música), que nos reunia

\footnotetext{
${ }^{2}$ Fonte: História do Colégio João XIII, <http://www.joaoxxiii.com.br/index.php/jxxiii/historia/>. Acesso em: 29 out. 2018.
} 
semanalmente para discutir os acontecimentos das aulas, estudar e planejar a semana seguinte, os planos bimestrais e as avaliações finais.

Os princípios que embasam a Educação Musical na escola constam num Documento-Base ${ }^{3}$, que expõe a fundamentação teórica referente às movimentações, expressão corporal atividades rítmicas, recitativos, atividades de relaxação, percepção auditiva, canto e improvisações. Está vinculado a outro documento mais denso ${ }^{4}$, que articula o Planejamento às etapas I e II do currículo escolar. Estudamos e discutimos esses documentos. O Documento-Base que possuo tem marcas das minhas leituras: chaves nas margens destacando um trecho, várias linhas sublinhadas com caneta azul e todos os subtítulos destacados com caneta vermelha e números dos itens circulados. No final desse documento, acrescentei mais canções à lista de sugestões que havia. Ao lado de cada canção, escrevi a lápis para quais turmas eu poderia ensiná-las. São minhas pegadas, meu norte. Por seu valor afetivo, nunca me desfiz dele.

Na leitura dos meus diários, para evitar a seleção de acontecimentos significativos, para então estabelecer entre eles conexões que imprimissem certa coerência, preferi ler bem devagar, apreciando o modo como eles foram escritos e pensados, as justificativas, os temas abordados. Principalmente, uma leitura atenta ao que ocorre com os meus sentimentos ao retroceder no tempo, até o ponto de partida da minha docência. O que haveria de implícito que precisaria ser explicitado? Como funcionava a rede de relações na qual eu estava inserida? Que leitura epistemológica poderia ser feita dos registros das aulas, da seleção das atividades e das avaliações? Por que razão meus diários foram preservados por tanto tempo?

\section{Material analisado}

Os diários de classe são cadernos onde registrei os planos de aula desenvolvidos. Cada diário corresponde a uma turma de alunos a quem ministrei aulas de música. De

\footnotetext{
3 Documento-Base, com 14 folhas finas datilografadas, entregues a todas as professoras de música em março de 1969. Acervo pessoal. Somente mais trade tive acesso à obra GAINZA, Violeta. Fundamentos, materiales y técnicas de la educación musical. Buenos Aires, 1977 e Willems, E. Las bases psicológicas de la educación musical. Buenos Aires: Eudeba, 1961.

4 Planejamento I e II (1969), com 26 páginas mimeografadas, correspondente ao currículo de Educação Musical da Educação Infantil. Acervo pessoal.
} 
1969 a 1972, atuei somente em turmas de Educação Infantil. Referente a esse período, tenho 12 diários. No período de 1973 a 1977, acompanhei as crianças até o $4^{\circ}$ ano e os registros estão contidos em 16 diários de classe. Os diários examinados na presente pesquisa referem-se aos cinco primeiros anos de docência (1969-1973), num total de 15 diários de classe.

\section{Passado datado e passado reconstruído: leitura dos diários}

Meus diários, se colocados lado a lado, formam uma sequência cronológica que representa o tempo em que estive ocupada com a docência. Contudo, se minha memória não reconhecer os fatos ali registrados como algo que aconteceu comigo, o tempo das experiências do passado se esvaziará na sucessão de fatos sem vida. Embora os registros tenham sua validade como comprovante de fatos concretos, a análise cronológica em si mesma é insuficiente para fazer ressurgir o mundo da vida de que são portadores. Os diários precisam ser recriados pela memória e interpretados, para que o tempo que eles registram possa ser articulado de modo narrativo, tornando-se um tempo verdadeiramente humano (RICOEUR, 1994), no qual a minha existência tem um sentido.

As narrativas que vou tecendo fazem a mediação que reorganiza em unidades temporais os acontecimentos dispersos em minha memória, imprimindo sentido às intenções, aos acasos e às ações isoladas, que perdem sua neutralidade impessoal ao serem reconfigurados pela narrativa. A identidade narrativa e seus caracteres de unidade e articulação interna permitem que eu me reconheça no que escrevo e me reencontre comigo mesma. Ricoeur (1991, p. 169) nomeou esse ato configurativo como "síntese do heterogêneo". Ao colocar-me por escrito, estou prolongando o trabalho criativo da “identidade narrativa”.

1969 - Primeira semana de aula: 7 a 10 de abril.

Esta semana inicio na Educação Infantil Colégio do João XXIII. Aqui todas as professoras são chamadas de tia; eu fui apresentada às crianças como tia Ledinha5. Terei

${ }^{5} \mathrm{O}$ costume de chamar a professora de "tia" estava associado à proposta democrática da escola. O abando do nome "tia" aconteceu possivelmente no período em que foi publicada a obra FREIRE, Paulo. Professora sim, tia, não. 
aula todas as tardes de segunda a quinta, onde atenderei crianças de 3 a 6 anos, Grupo 2, Grupo 3, Nível 1 e $1^{\circ}$ ano. As aulas de música acontecem duas vezes por semana, sempre com a turma dividida em dois grupos, um fica comigo na sala de aula, o outro acompanha a professora de classe para outra sala, onde realiza atividades de artes, hora do conto ou jogos. Para os pequenos a aula dura 45 min, para os demais a aula é de 1 hora.

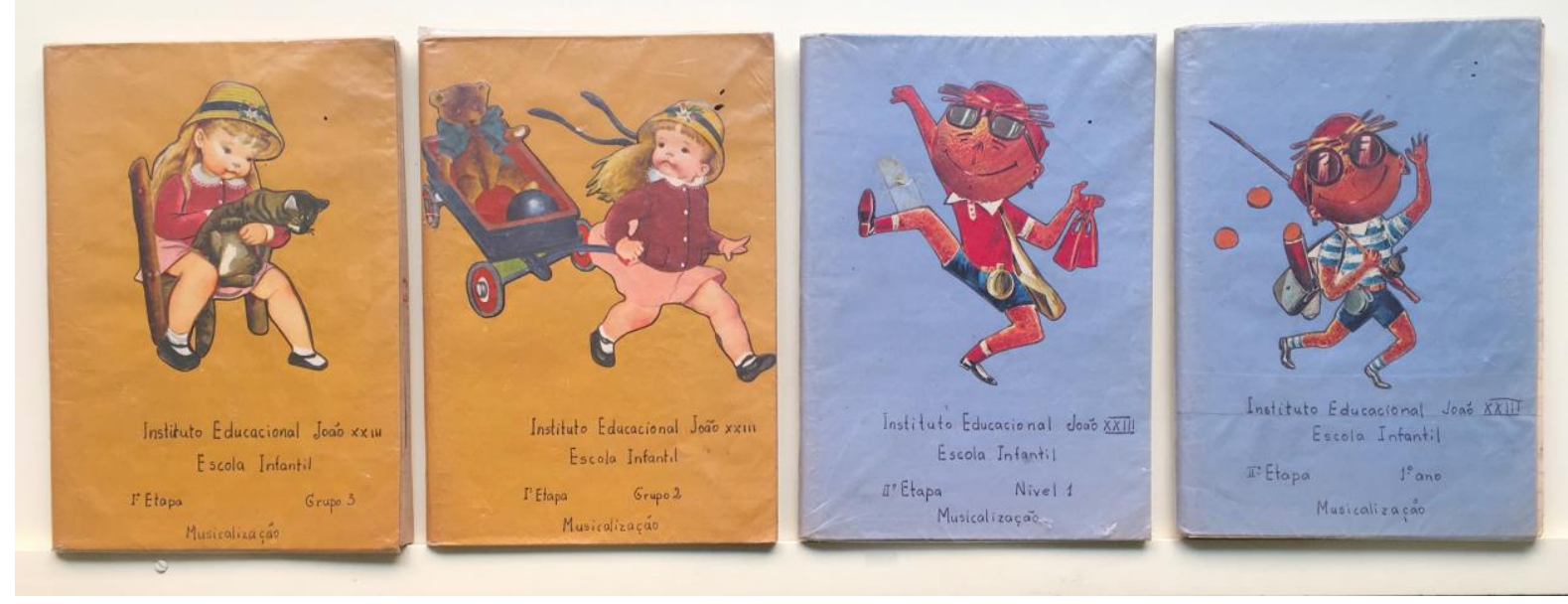

Figura 1 - Diários de classe, 1969.

Estes são meus diários do primeiro ano de trabalho. Todos encapados com papel colorido, revestido de plástico transparente. Na capa colei uma figura colorida, recortada de livrinhos de história, escrevi o nome da escola, etapa e turma. Logo abaixo escrevi Musicalização. Na primeira página de todos os diários consta o nome das crianças; à esquerda do nome há as letras A e B que identificam o grupo a que pertenciam. Essa divisão foi uma sugestão da professora de classe.

Minha primeira aula foi no Grupo 3, com crianças de 4 anos, da turma da tia Tânia. Nunca havia trabalhado com crianças tão pequenas. Se elas não quisessem participar, eu ficaria sem ter o que fazer... Pensei em conquistá-las com canções graciosas e atividades de movimentação.

A identificação das partes da aula está escrita com canetinha colorida; as atividades desenvolvidas com caneta tinteiro azul. Minha letra é bem torneada, fiz caligrafia no curso primário. Os diários foram preenchidos com calma, depois de ter 
desenvolvido as aulas. Na verdade, são relatórios dos acontecimentos das aulas. Inclusive os feriados estão anotados.

Organizei assim:

No alto da página, bem no centro da folha, escrevei Plano de aula. Na linha de baixo, junto à margem esquerda, a identificação do plano: Data e Horário. Se colocados todos os diários lado a lado, posso identificar em qual sala de aula eu estava em cada minuto da semana. Na identificação seguinte, Área de estudos, são anotados os enfoques das aulas, como canção dramatizada, jogos rítmicos, revisão de atividades, ou outro. $\mathrm{Na}$ linha mais abaixo, escrevi as Intenções da aula - essa era a parte mais complicada de fazer. Tinha de haver uma intenção, então escrevi: Desenvolver a percepção do som e do ritmo. Proporcionar a saudável atividade do sistema circulatório e respiratório. Por fim, constam as Atividades de desenvolvimento, escritas bem no centro da folha.

No espaço das atividades de desenvolvimento, desenhei um passarinho bem colorido ao lado do título da canção e algumas figuras rítmicas saindo do seu bico; ao lado, escrevi o título Canção historiada Tiu-i. Logo abaixo do título, escrevi a letra da música, com caneta verde e letra script.

Aproveitei a letra da canção e criei uma pequena história para servir de roteiro para a aula. Foi desse modo que criamos, minha colega e eu, a canção historiada, que mais tarde denominamos canção dramatizada.

A canção dramatizada funcionou bem durante três anos, mas nem sempre a história e a música se encaixavam. Algumas vezes as atividades musicais não eram desenvolvidas porque não se encaixavam no roteiro da história; outras vezes acontecia o contrário, eu me concentrava nas atividades musicais e esquecia de retomar o enredo, deixando a história sem nexo.

Outra atividade que abandonamos foi o "bom-dia cantado". Todos os dias entrávamos na sala de aula cantando Bom dia! (Sol-Mi-Dó). Nos momentos de improvisação, esse pequeno intervalo era repetido por todos. Mudamos as notas do bom-dia, mas a influência daqueles intervalos nos improvisos das crianças era dominante. O jeito foi abandonar o hábito do "bom-dia cantado". 
Hoje, ao reler os diários, encontrei, muito raramente, anotações a lápis nas margens dos cadernos dizendo “Difícil”, “Muito bom”, “Excelente”, mas fiquei sem saber se foi difícil para mim ou para as crianças; se foi muito bom ou excelente porque as crianças se envolveram, ou porque o plano fora integralmente desenvolvido. Os detalhes coloridos e os desenhos que enfeitam as páginas trouxeram mais lembranças do que o registro das aulas. Eram as aulas que eu queria lembrar, mas esses detalhes me capturaram. Eles representam a minha relação com as crianças, o meu empenho em fazer um bom trabalho. Há muito capricho na escolha das cores, nas figuras coladas e até nas faixas de papel colorido que colava em cima dos erros, para não precisar arrancar as folhas do diário. Meu envolvimento era total e amoroso.

As atividades realizadas nos finais dos semestres letivos (junho e novembro) repassam os conteúdos trabalhados e preparam as crianças para uma apresentação aos pais, que chamávamos de avaliação. Era um momento importante de exposição dos objetivos da Educação Musical e apresentação da produção das crianças, para que os pais acompanhassem o processo de seus filhos. A lembrança que tenho desses encontros mistura prazer e ansiedade. Prazer porque era um evento que valorizava meu trabalho, e muita ansiedade porque eu ficava exposta aos comentários, avaliações e críticas dos pais e dos colegas.
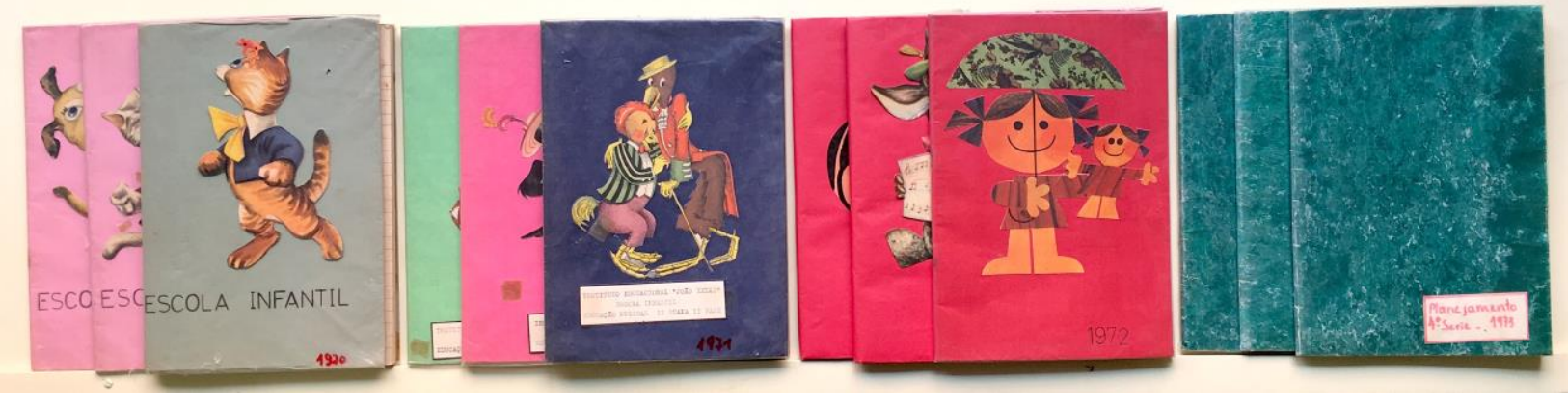

Figura 2 - Diários de classe 1970-1973.

1970 - Semana de 26 a 29 de maio.

Nesse ano tenho duas turmas de Nível 1 e as aulas de ambas estão registradas no mesmo caderno, com observações a lápis quando havia alguma alteração. Nesse diário há um encarte feito com folha azul, sem linhas, identificado com letras vermelhas: Planos da 
Avaliação $1^{\circ}$ Semestre. Ali estavam registradas, com detalhes, todas as aulas apresentadas aos pais, os objetivos de cada atividade e seu desenvolvimento. No diário de cada turma, o dia da avaliação está registrado em destaque ocupando toda a página ${ }^{6}$. Esses detalhes me dizem que os momentos de avaliação eram importantes no meu trabalho. Dessas apresentações dependia o valor atribuído à música no currículo escolar e, com certeza, a presença das professoras de música na escola.

No plano do dia 16 de novembro, há o desenho de uma pandeireta em todas as atividades de movimentação e ritmo. Um círculo grande, formado por pontos que representam a posição das crianças no espaço, com flechas que indicam a direção para dentro e para fora; as recomendações alertando para manter a unidade durante as atividades rítmicas, tudo leva a crer que naquele dia eu estava preocupada com a apresentação para os pais. O objetivo definido no cabeçalho do plano é muito singelo: Exercitar a percepção auditiva. Estaria eu pensando que o sucesso do desempenho das crianças dependia do treino auditivo? Talvez naquele tempo essa crença fizesse sentido...

A seguir, me deparo com uma atividade de expressão corporal extraída do livro de Patricia Stokoe $(1967)^{7}$. Pude até localizar a página onde consta a sua proposta "El cuento animado" (p. 54-56), formado pela sequência de seis fotos de expressão corporal. São cenas lindas de uma menina que inicia em posição fechada sobre si mesma, aos poucos vai se abrindo e erguendo-se do solo com a face voltada para o sol; apoia-se num pé, depois no outro; com os dois braços bem abertos, atira para o alto uma das pernas e grita: Bom dia, sol!

Frequentei vários cursos de expressão corporal em que a proposta do "conto animado" de Patricia Stokoe foi explorada, inclusive quando participei de uma oficina ministrada por ela. A expressão corporal foi muito valorizada na época, fez parte da minha formação no João XXIII ${ }^{8}$ e formação acadêmica ${ }^{9}$, aparecendo nos meus diários de diferentes formas.

\footnotetext{
${ }^{6}$ As avaliações do $2^{\circ}$ semestre constam dos diários nos dias Grupo 221/11; G3 25/11; e 3, 22/6; Nível 1 em 23/11.

${ }^{7}$ STOKOE, Patricia. La expresión corporal y el niño. Buenos Aires: Ricordi Americana, 1967.

${ }^{8}$ Curso de "Expressão Corporal ministrado por Luis Arthur Nunes, 12 de abril a 22 de dezembro, 25 horas. Departamento de Integração Artística e Cultural, Instituto Educacional João XXII, Porto Alegre, 1969. Curso de Expressão Corporal. Estúdio Ligia de Oliveira Callage, 17 a 28 de julho, 1972.

${ }^{9}$ A disciplina ART 114 - Expressão Corporal I e ART 550 - Expressão Corporal I eram oferecidas no Instituto
} 
Essa e outras constatações revelam que muitas ideias registradas nos meus diários não eram propriamente minhas, mas extraídas de outros autores; que a estruturação dos planos não era uma criação minha, mas seguia o Documento-Base da escola. No entanto, antes mesmo de serem copiados ou seguidos, os valores latentes já estavam sendo elaborados através da identificação-com. Foi a partir dessa alteridade assumida que os autores que conheci, as estratégias e os saberes de outras pessoas foram gradualmente interiorizados, tornando-se traços estáveis da minha identidade profissional.

Por paradoxal que possa parecer, eu só me encontro nos diários que escrevi quando minha memória reconhece minhas marcas deixadas nos planos de aula. Mesmo que eu tenha identificado a origem das ideias que pensei serem minhas, ainda assim elas atestam que eu vivi intensamente aquele tempo.

1971

Nesse ano, o Colégio João XXIII muda-se para sua sede própria, num terreno amplo que abriga todos os níveis de ensino. A Educação Infantil passa a ter uma sala de música com um piano à minha disposição e tapetinhos para as crianças sentarem no chão. A duração das aulas e a sistemática de divisão das turmas permanece a mesma.

Os diários de 1971 apresentam a novidade de inserir comentários sobre o aproveitamento musical das crianças, como também a inclusão de um mapeamento dos conteúdos de Educação Musical. O mapeamento funcionava como um diagrama que articula as atividades que se relacionam entre si numa determinada área da Educação Musical: improvisação, entoação, expressão corporal, movimento, ritmo e percepção auditiva.

de Artes da UFRGS, conforme consta no documento por mim solicitado à secretaria da instituição: Atestado n. 722/74. Acervo pessoal. 


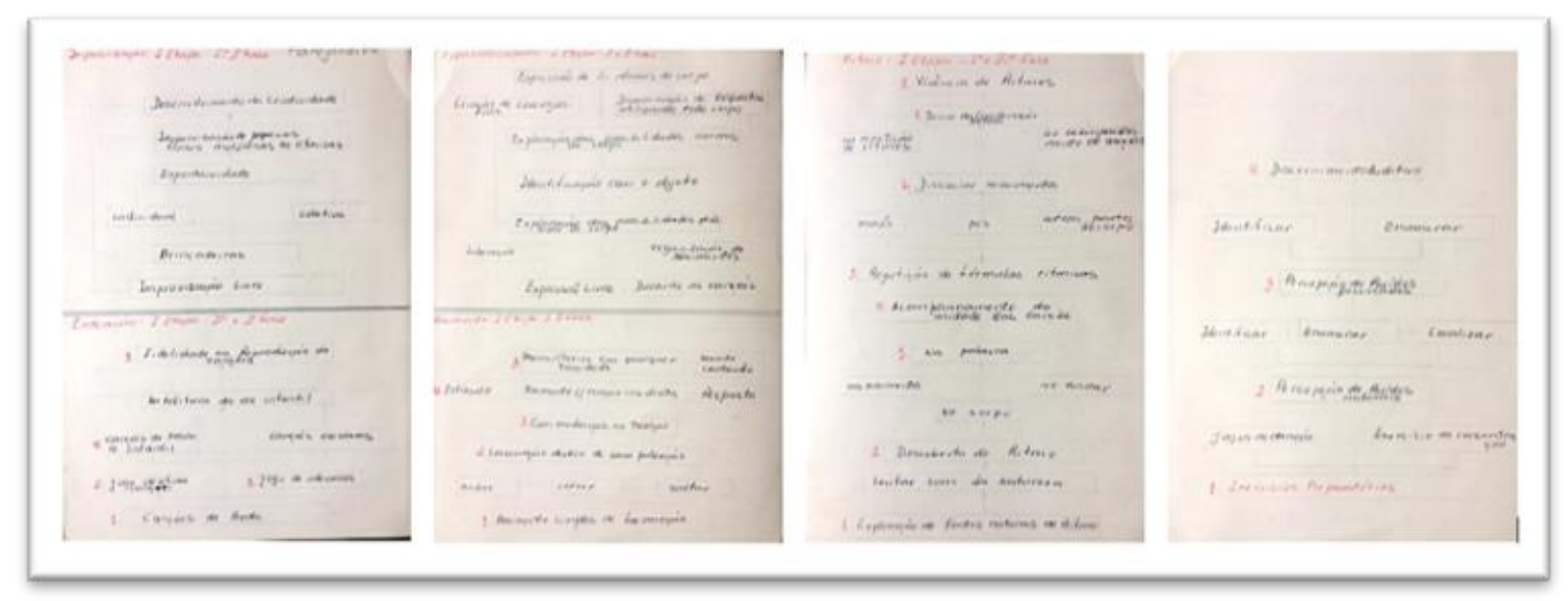

Figura 3 - 1971, mapeamento dos conteúdos da Educação Musical Etapas I e II.

$\mathrm{Na}$ folha mimeografada que acompanha o diário do $1^{\circ}$ ano, escrevi a tinta no canto esquerdo da primeira folha: mudança no planejamento do $2^{\circ}$ semestre. A leitura dos planos de aula esclarece do que se trata.

$1971-1^{\circ}$ ano

Plano de aula, dia 29 de março, segunda-feira.

Esse ano tenho duas turmas de $1^{\circ}$ ano, uma pela manhã, outra à tarde. As aulas de música iniciaram dia 29 de março. Neste dia pensei testar a memória das crianças. Selecionei dez canções trabalhadas no ano anterior e as reproduzi em bocca chiusa, questionando as crianças se reconheciam as melodias sem a letra. Sob o título de Avaliação, escrevi o que segue:

A melodia mais lembrada foi o Tubarão. Creio que é devido à série de trabalhos que foram realizados com essa melodia. Ela foi explorada em: ritmo da palavra, pulsação, audição interior, e ainda foi recurso para os exercícios da prof. de classe no ano que passou. Nota: a maioria das músicas deveriam ter sido exploradas como foi o Tubarão. Teria havido maior fixação. Não estão muito esquecidos, falta é conjunto. Desacostumaram cantar em grupo. Quanto à repetição de ritmo, posso continuar sem me deter em recordações prolongadas.

$1971-1^{\circ}$ ano

Plano de aula, dia 5 de maio, quarta-feira. 
Após desenvolver a aula, dedico alguns minutos à avaliação sobre as atividades desenvolvidas pelas crianças.

As crianças tiveram muita dificuldade na movimentação com célula rítmica. O trabalho para chegar a isso deverá ser recomeçado. É preciso treinar a memória, estão muito dispersivos, $80 \%$ esqueceram 0 acompanhamento de canções, principalmente turno da manhã, a audição interior está fraquíssima. Estão cantando muito grave.

1971 - Grupo 2

Plano de aula, dia 9 de agosto, segunda-feira.

Nesse dia fiz uma revisão das atividades realizadas no $1^{\circ}$ semestre. Iniciei com uma conversa informal perguntando se alguém havia cantado em casa durante as férias. Em seguida, realizei as movimentações de costume, dedicando maior ênfase às atividades de expressão. A intenção era prepará-los para as improvisações de ritmo e melodia que faria a seguir. No comentário avaliativo que escrevi sobre essa turma, assim me referi sobre o aproveitamento das crianças:

As crianças foram muito criativas em todas as improvisações. Estavam à vontade. Até o último dia de julho, as crianças não caminhavam em diferentes andamentos, hoje conseguiram fazer isso. Não houve regressão durante as férias. Estão repetindo ritmo sem o auxílio de palavras. No $1^{\circ}$ semestre não conseguiam.

Por que esses comentários aparecem somente agora no terceiro ano de minha docência? Retornei aos diários dos anos anteriores e confirmei a ausência das crianças nos meus planos de aula. Uma que outra pauta musical reproduz os improvisos das crianças, nada além disso. Essa constatação me entristeceu, fiquei desapontada comigo mesma, porque minhas aulas foram sempre planejadas pensando nas crianças e registradas com esmero, de forma que representassem claramente os acontecimentos da aula. Por que razão eu não registrava as condutas das crianças?

A prática e os registros sobre essa prática parecem não caminharem juntos. Não posso subestimar a importância da aquisição de uma linguagem profissional específica para descrever os acontecimentos da sala de aula. Autores como Berliner (2000) e 
Marcelo Garcia (2011) fazem referência a esse tipo de dificuldade, como também à necessidade sempre presente de melhorar a competência profissional e pessoal dos professores. No entanto, apesar de poder contar com um grupo de apoio e assessoramento sistemático, meus diários mostram fragilidades que não consegui evitar.

No caso das aulas de música, é particularmente difícil planejar atividades para serem realizadas num espaço sem classes e sem cadeiras, como é o caso da sala de música. Na sala de aula, onde as crianças permanecem com a professora de classe, as mesas são previamente agrupadas, formando grupos que asseguram o bom andamento dos trabalhos. Seus nomes aparecem identificando os trabalhos expostos nas paredes. É um espaço que combina liberdade e limites, identidade e pertencimento; um espaço que caracteriza o grupo de crianças como "uma turma". Quando as crianças são retiradas desse espaço, os pontos de referência usuais desaparecem e outros precisam ser construídos. Muitas vezes, enfrentei situações que poderiam ser consideradas como indisciplina, não fosse a leitura da simbologia do movimento presente nos processos de socialização das crianças (LAPIERRE; AUCOUTURIER, 1986). Penso que isso poderia justificar a minha concentração prioritariamente na organização das ações do professor, deixando em segundo plano a observação do comportamento das crianças.

Um fator que possivelmente impulsionou a mudança de perspectiva nos meus diários pode ter sido o processo avaliativo realizado duas vezes ao ano, que exigia de mim uma postura coerente com relação aos objetivos da educação musical. Minhas avaliações eram incluídas nas avaliações gerais que as professoras de classe entregavam aos pais uma responsabilidade suficientemente forte para fazer com que eu voltasse o meu olhar para as crianças e não só para o modo de conduzir as aulas.

1972

Estou no terceiro ano do curso de Licenciatura em Música, o regime da universidade passou a ser semestralizado. Por não poder mais conciliar meus horários, a partir do $2^{\circ}$ semestre precisei cancelar o curso de Composição e Regência que até então cursava concomitantemente. Além das disciplinas do Instituto de Artes, começo a frequentar as disciplinas oferecidas pela Faculdade de Educação. No $1^{\circ}$ semestre: Evolução da escola brasileira e Psicopedagogia do desenvolvimento individual; no $2^{\circ}$, 
Psicologia da Aprendizagem e Estrutura e funcionamento do ensino de $1^{\circ}$ e $2^{\circ}$ graus. A reforma do ensino, Lei 5.692, começa a ser implantada nas escolas e a Faculdade de Educação movimenta-se para atender as exigências legais. O meu olhar para a docência é influenciado pelos estudos na faculdade e pelo clima de mudança que se instaura no contexto brasileiro.

Decorridos quase 60 anos, estou consciente de que mudei muito, que a interpretação dos registros pode ser distinta do modo como foram originalmente vivenciados. Contudo, é sempre do ponto de vista do presente que o meu passado é revisitado.

A leitura dos diários do ano de 1972 foi realizada com a mesma sistemática que a dos anteriores. Li todos os planos, apreciando seu conteúdo, enquanto minha memória fazia o contraponto necessário para que eu me apropriasse do que havia escrito.

Os diários de 1972 me encantam pela ampla exploração das vivências espaciais e pela exploração variada das possibilidades sonoras e percussivas do corpo. Todos os diários apresentam esse enfoque. Balançar o corpo para um lado e para outro, esticar e encolher, movimentar e deter-se, acelerar e diminuir o passo seguindo o andamento da música eram experiências em que as crianças e eu partilhávamos o mesmo tempo vivido, o mesmo estado psíquico. Eram experiências de felicidade mediadas pelo corpo.

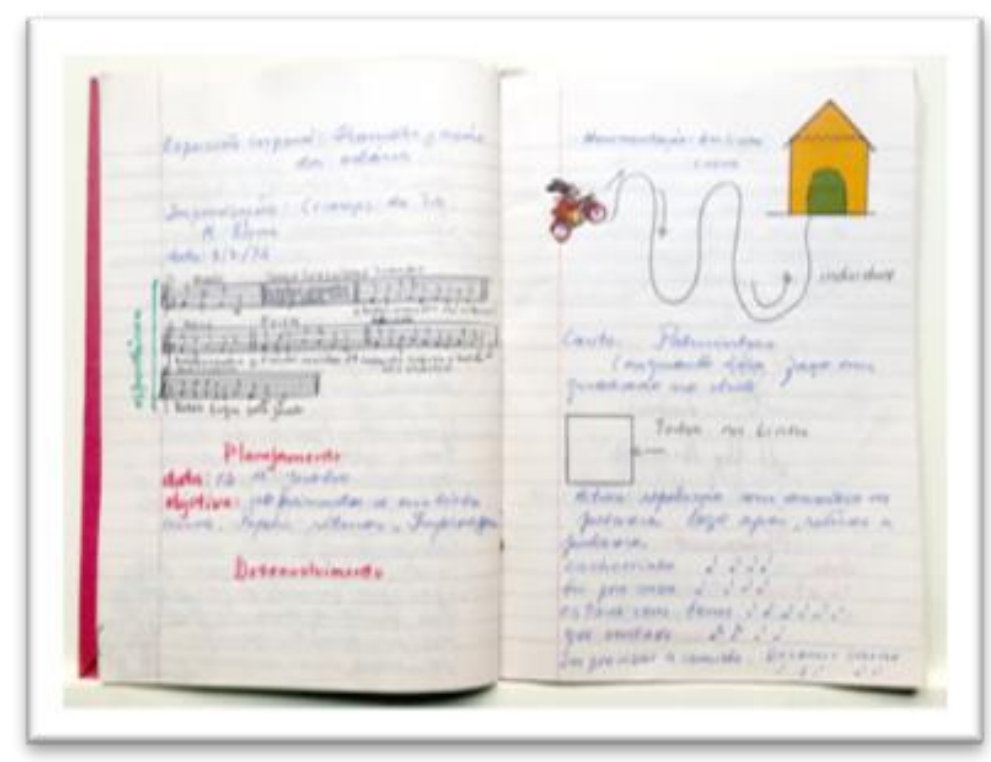

Figura 4 - 1972, Diário Grupo 2 e 3. Plano de aula, dia 12 de junho, segunda-feira. 
Nas reuniões da equipe de música da escola, a professora de flauta doce, ao receber no $2^{\circ}$ ano os alunos egressos da Educação Infantil, seguidas vezes queixou-se da dificuldade que eles apresentavam de manter a pulsação em atividades de conjunto. Nesse ano resolvi intensificar o atendimento às necessidades das crianças, apoiando-me em autores que me ensinaram a trabalhar a expressividade motora e musical das crianças. As avaliações descritivas do desempenho musical das crianças estão registradas esporadicamente no interior dos diários. O fato novo é que para cada turma criei um encarte avulso intitulado Controle das avaliações, no qual o desempenho das crianças foi rigorosamente controlado: as atividades de canto, percepção, som, ritmo, criatividade (som, ritmo e expressão corporal), movimento (percepção e execução), além das observações singulares que caracterizam cada criança.

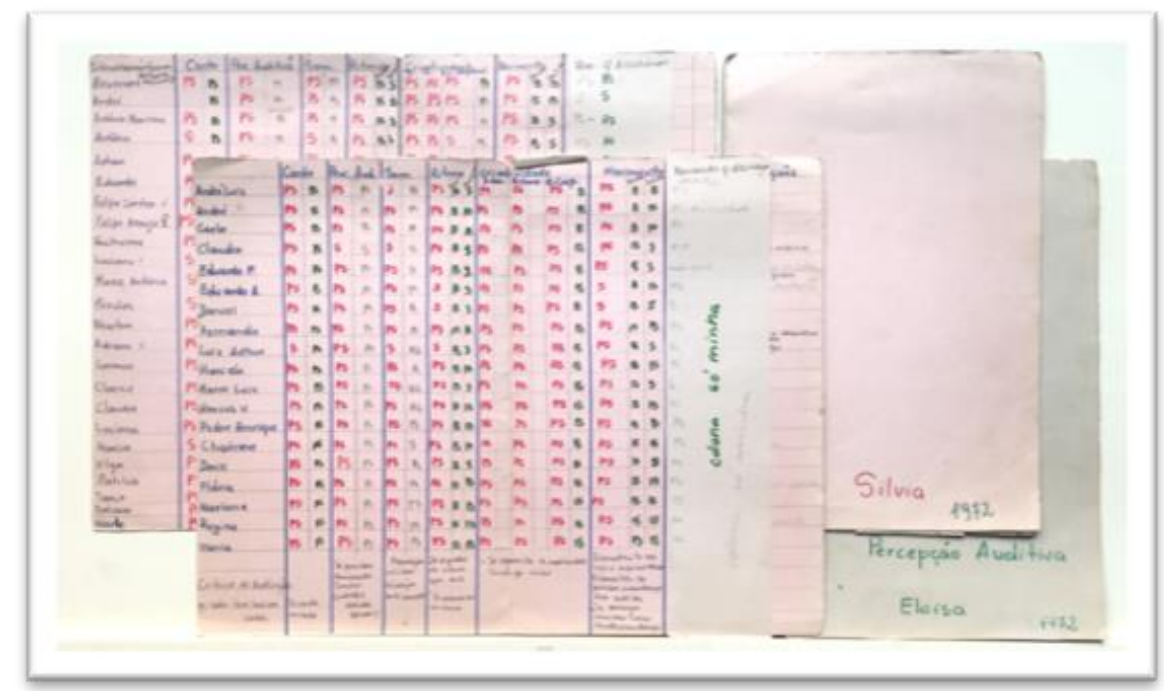

Figura 5 - Diários 1972. Controles das avaliações (encartes).

Eu me orgulhava de ser assim. Dentre tantas formas de acompanhar o aproveitamento dos alunos, preferi essa que me dava um trabalho imenso. Apesar disso, eu me sentia coerente com o desejo de ser uma professora competente, atenta a todos os alunos, não apenas a alguns.

Minhas colegas, professoras de classe, também preenchiam avaliações que abrangiam uma enormidade de dados. Elas diziam, de brincadeira, que as fichas eram "do berço ao túmulo", pois havia descrições sobre todos os aspectos da vida da criança, na 
época: aspectos motores, cognitivos e afetivos ${ }^{10}$. Elas tinham em mãos inclusive os dados dos anos anteriores, que lhes foram entregues pela professora do ano anterior, como “ritual de passagem" da turma. Da minha parte, as fichas de avaliação mostravam que o meu trabalho era tão detalhado quanto o delas.

Aprender a planejar, elaborar os objetivos e acompanhar a aprendizagem dos alunos acabou me inserindo num processo rotineiro, marcado pelas relações sociais próprias de um grupo de professoras com as quais compartilhei significados subjetivos. Religar esses vínculos será essencial à produção das narrativas desse período.

1973

Nesse ano, assumo como professora de música em uma escola noturna de $2^{\circ}$ grau, o "Colégio Municipal Emilio Meyer". Meus alunos são adolescentes e adultos que trabalham durante o dia. Pela primeira vez, enfrento dificuldades ao adequar os conteúdos da Educação Musical ao contexto sociocultural e interesses dos alunos. Em nenhum momento de minha formação acadêmica foi abordada a história da música popular brasileira, sendo precisamente esse o conteúdo a que devo me dedicar daqui por diante.

No Colégio João XXIII, a professora de Educação Musical da $3^{\mathrm{a}}$ e $4^{\mathrm{a}}$ etapas afastouse, abrindo a possibilidade de eu acompanhar meus alunos na passagem para $2^{\circ}, 3^{\circ}$ e $4^{\circ}$ anos. Além das professoras de classe, minha companheira de trabalho mais próxima passa a ser a professora de flauta doce, com quem divido as turmas nos horários destinados às aulas de música. Tia Beatriz é uma professora muito experiente e com formação específica no instrumento que ensina. Minha sala de música mudou, é ampla e posso organizar as aulas contando com os instrumentos musicais, como xilofones e instrumentos de percussão simples.

\footnotetext{
${ }^{10}$ Influência clara da educação tecnicista que começa a se impor nas escolas: BLOOM, Benjamim S. Taxonomy of educational objectives Português Taxionomia de objetivos educacionais. Porto Alegre: Globo, 1972. 2 v.
} 
Hoje é 26 de março, segunda-feira.

Inicio o ano letivo com muitas expectativas, minha rotina de trabalho está bem diferente. Meus planos de aula incluem atividades voltadas à alfabetização musical. Trabalho com leitura em cartões e faixas contendo círculos que representam as figuras rítmicas, intercaladas com sinais de silêncio. A pedido da professora de flauta doce, ensino canções com os nomes das notas e desenvolvo jogos envolvendo intervalos musicais. Tudo parece girar em torno da leitura musical.

Na contracapa de todos os diários constam os planos de ensino, que dessa vez são organizados em colunas justapostas: objetivos, conteúdos, procedimentos, recurso didático e avaliação. Cada objetivo está alinhado horizontalmente com o seu conteúdo, procedimentos, recursos e forma de avaliação. Os objetivos expressam os comportamentos que eu deveria observar em sala de aula: "Ler as notas musicais, localizar na pauta e executar no instrumento musical; reconhecer e distinguir unidade e ritmo; movimentar-se obedecendo a um ritmo dado", e assim por diante.

\section{3 - Diário $2^{\circ}$ ano}

As aulas iniciaram dia 26 de março. O primeiro objetivo de aula foi "Sondar o nível da turma através de um plano-teste baseado no comportamento de saída do ano de 1972". Nas Atividades de desenvolvimento, escrevi: "Ao iniciar este ano as crianças deverão ser capazes de:", e listei uma série de objetivos e atividades ensinados no ano anterior. Essa era uma maneira não só de verificar o aproveitamento das crianças, mas, também, de comprovar para mim mesma que havia preparado adequadamente as crianças para o trabalho a ser realizado no $2^{\circ}$ ano. Se as crianças foram bem preparadas por mim, certamente demonstrariam suas aquisições.

Após ter realizado as atividades-teste, nas observações avaliativas, escrevi: “A turma está muito bem. Notei dificuldade, na turma da Marisa, em ritmo e estímuloresposta. As canções foram de razoável afinação. Quanto ao canto em conjunto, houve muito individualismo, estava desparelho." 
Com base no que escrevi nos diários de 1973, certamente eu acreditava que reproduzir igual significava que a aprendizagem tinha acorrido. O binômio ensinaraprender tinha a força de me fazer crer que o método de ensino era a chave da aprendizagem das crianças. Foi somente na década de 1980-1990 que a ruptura epistemológica realmente aconteceu (MAFFIOLETTI, 2018). Até então, eu pensava como qualquer professora do meu tempo: “Isso você já sabe porque eu já ensinei”.

Em vista do modo fluido como as crianças viviam a música, eu achava estranho dizer a elas, por exemplo, que o "compasso é a divisão da melodia em partes iguais quanto à duração" (Diário de classe 1973, $4^{\circ}$ ano, dias 9 e 16 de abril), mas não passava de um estranhamento, não estava muito claro para mim, apenas repetia do mesmo modo como me ensinaram, "sempre foi assim".

$1973-3^{\circ}$ ano

Hoje é dia 13 de agosto, segunda-feira.

Organizo as crianças bem à minha frente e inicio um diálogo.

Seguro um cartão contendo uma semínima e pergunto:

Que figura é essa ل ? - Semínima.

Seguro um cartão contendo duas colcheias e pergunto: E esta Jd? - Colcheia.

Seguro um cartaz contendo um ritmo composto de semínimas e colcheias e pergunto: Quantas semínimas tem aqui d JdJ? - Duas.

Quantas colcheias tem aqui ل J Jd? - Uma colcheia.

Intrigada, solicito que reproduzam o ritmo, a turma reproduz corretamente.

E então, quantas colcheias são? - Uma.

A situação ficou tensa, uma criança resolve explicar: É uma só colcheia, porque vale1.

Essa cena aconteceu nas duas turmas do $3^{\circ}$ ano, várias crianças afirmaram que havia uma colcheia e não duas. Ao concluir a aula, escrevo a seguinte observação: “Confusões assim foram sendo solucionadas a partir de pergunta e resposta". Não há registros sobre o que pensei naquele momento. 
No período de 1970-1980, os problemas de aprendizagem eram atribuídos à falta de coordenação motora, lateralidade não definida, ou problemas de discriminação visual e auditiva. As incompreensões das crianças, como as descritas acima, eram "coisas de criança”, "próprias da idade”.

1973

Diário de classe, $4^{\circ}$ ano, 14 de maio, segunda-feira.

Notei que as crianças das duas turmas estão cantando muito pouco e em registro grave. Devo fazê-las cantar mais e brincar mais com as canções rodas cantadas, por exemplo. Preciso reforçar os exercícios de movimento sonoro.

Os arranjos instrumentais envolvendo a flauta doce, xilofones e instrumentos de percussão simples eram estruturados a partir de intervalos do acorde sobre a tônica, praticamente sobre as notas dó-sol-dó e variações, sem espaço para o desenvolvimento de uma estrutura pessoal de expressão. Após uma tentativa de deixá-los livres para inventarem suas melodias, escrevo no diário o que segue:

1973

Diário de classe, $4^{\circ}$ ano, dia 6 de agosto, segunda-feira.

A exploração dos instrumentos musicais, livremente, durou 8 minutos. No $1^{\circ}$ grupo houve um início de conjunto, mas logo tudo se perdeu, notei um esgotamento de ideias. Não souberam concluir o trabalho, ficaram perdidos precisando da minha intromissão. $02^{\circ}$ grupo formou vários conjuntos, combinaram o que iriam executar e ensaiaram ritmos. Foi ótimo. A exploração foi de 2 minutos e a realização de conjuntos foi espontânea e organizada.

Cria-se dentro de mim um dilema entre valorizar a estrutura pessoal dos improvisos e os ensaios que envolviam os arranjos com base nos métodos de ensino da 
música que estudávamos em equipe, principalmente método Orff (1961) e método Willems (1961).

Ao mesmo tempo, a psicologia educacional de Benjamim Bloom (1972), que defendia a estrutura hierárquica dos objetivos educacionais, era discutida no âmbito das universidades e posteriormente nas escolas da rede pública". Todo o sucesso das aprendizagens escolares era atribuído ao planejamento criteriosamente organizado dos professores. Havia, inclusive, uma lista de verbos adequados aos comportamentos referentes ao conhecimento, compreensão, aplicação, análise, síntese e avaliação.

A maneira como eu experimentei todos esses acontecimentos transparece nos registros daquele período. Foi em 1973 que uma colega da Educação Infantil, professora também da rede pública, me alertou: "Você sabia que a canção Marcha Soldado será proibida nas escolas? É porque a letra diz que a cabeça do soldado é de papel...”. Esse era o clima da época, que expressa o sentimento de "vigilância que os professores sentiam ao exercer sua profissão" (LOURENÇO, 2010, p. 97). É praticamente impossível compreender as contradições, as tensões e os problemas da minha prática docente sem vincular os meus diários ao contexto sociocultural e político no qual eu estava inserida.

A consciência de ser eu mesma todos esses anos, apesar de ter modificado várias vezes o modo de pensar, tem me permitido preservar no ser professora a minha existência como pessoa. Essa originalidade me identifica, não concorre com ninguém, apenas se mostra.

A perspectiva teórica que guiou minhas reflexões exigiu de mim caminhar ao lado do meu processo, reconhecendo que a subjetividade presente no ato de "fixar na escrita o que se tenta pegar no ar, o que foge e escapa a cada tentativa é um trabalho ao mesmo tempo laborioso, sedutor e consideravelmente formador (PASSEGGI, 2008, p. 64).

O problema é que "[...] nunca estamos numa posição absoluta de inovadores, mas sempre inicialmente numa situação relativa de herdeiros [...] das coisas já ditas, ouvidas e recebidas (RICOEUR, 1997, p. 379). Nossa história de vida está sempre em movimento, não cessa de ser reconfigurada por todas as histórias que contamos sobre nós mesmos.

\footnotetext{
${ }^{11}$ Posteriormente difundido nas escolas estaduais, mediante treinamento oferecido pela Secretaria Estatual de Educação RS, conforme documento: Instrumentalização da taxinomia os objetivos educacionais. Programa de assistência pedagógica às escolas. Secretaria de Educação do Estado do Rio Grande do Sul, 1977.
} 


\section{Buscando um sentido de totalidade}

Há um tempo passado fixado nas páginas dos diários. Há também um tempo passado reconfigurado no presente, em que as cenas contam com registros reais, mas são revestidas de significados capturados pela memória em diferentes tempos e espaços vividos. Há ainda o tempo da configuração narrativa expresso na escrita, que atua no presente, recua ao passado e projeta-se para o futuro, sem perder de vista a totalidade que dá coerência ao texto. Por fim, há o tempo do leitor, que precisa ser considerado para que a história narrada possa ser seguida. A complexidade da escrita autoral, que tantas vezes congela as palavras, está em coordenar esses diferentes tempos numa configuração que correlaciona tempo e narrativa (RICOEUR, 2012).

No momento em que escrevo este artigo, minhas reflexões não procuram desvendar a verdade sobre fatos que vivi, mas me reencontrar nas práticas cotidianas registradas e datadas nas páginas dos meus diários. Importa mais o impasse epistemológico provocado pela mudança na perspectiva dos diários e o estranhamento experimentado ao me perceber como um outro no papel de leitor e produtor de minhas próprias narrativas.

$\mathrm{O}$ ato de escrever a minha história fez surgir os jargões do meu tempo: avaliações “do berço ao túmulo”, “Isso você já sabe porque eu já ensinei”, “coisa de criança”, ou as incongruência que desrespeitam o modo como as crianças sentem a música, porque “sempre foi assim”. Reconheço que não era só na área da música que essas práticas aconteciam. Na época, os métodos de alfabetização do idioma materno faziam as crianças repetir: "Ivo vê a uva", "O poço é de aço" ${ }^{2}$, da mesma forma distante dos significados vividos pelas crianças no cotidiano.

Chego mesmo a pensar que os métodos de alfabetização incorporam narrativas praticadas no discurso comum, deixando de lado as subjetividades das crianças. Não tenho vergonha de contar que por um bom tempo acreditei que as propriedades da música, melodia, ritmo e harmonia correspondiam às estruturas de pensamento musical infantil. Tanto é que os planejamentos bimestrais priorizavam ora a melodia, ora o ritmo, raramente a harmonia, por ser de compreensão mais complexa. Foi depois de conhecer

\footnotetext{
${ }^{12}$ Lembranças de minha filha fazendo a lição de casa...
} 
os estudos de Mary Louise Serafine (1983) que compreendi a confusão que havia entre os elementos da música utilizados para análise e estudo de épocas e estilos com os processos cognitivos humanos para perceber a música. Revendo os autores que me influenciaram, observo a sintonia do meu pensamento com o "planejamento e a organização do ensino" aprendidos na faculdade e na escola, por mim e por minhas colegas, com quem tive forte vínculo afetivo. Como defende Ferrarotti (2013, p. 65), “O conhecimento integrante de uma pessoa torna-se, assim, o conhecimento interagente de outra. O coletivo social e o universal singular ilustram-se mutuamente".

Minha trajetória mostra que estive mais fechada em mim mesma nos dois primeiros anos de docência. A adoção sem reservas do Documento-Base da escola substituiu a autonomia que mais tarde se mostra em meu trabalho, ao escolher novas estratégias para garantir o desenvolvimento de uma estrutura pessoal na improvisação musical das crianças. Nesse momento, obedeço a mim mesma e me sinto mais livre para alcançar maior autonomia na prática pedagógica.

A abertura para o conhecimento do outro começa a se mostrar através da presença das crianças nos meus diários. É desse modo que percebo metaforicamente os vestígios da alteridade como possibilidade de conhecimento de si mesmo. Ler os diários, portanto, constituiu um lugar privilegiado de afeição, em que o embate subjetivo com texto escrito transborda para o terreno da imaginação, no qual o si e o diverso de si encontram-se na constituição da identidade narrativa que gerou a minha história de vida (RICOEUR, 1991).

Algo permanece forte e vivo em minha maneira de ser: o desejo de aprender, a energia de insistir no que me parece difícil e a paixão que pinta, com canetinha colorida e letra bem torneada, os registros da minha existência.

Retomo a epígrafe que inicia o presente texto, porque ela sintetiza a complexidade do tempo mediado pela narrativa: "o passado se torna presente e se transfigura, contaminado pelo aqui e o agora" - que já não é mais o mesmo depois que tornei pública a minha breve história de vida. 


\section{Referências}

ABREU, Delmary. História de vida e sua representatividade no campo da educação musical: um estudo com dois educadores do Distrito Federal. InterMeio: PPG, Campo Grande, v. 23, n. 45, p. 207-227, jan./jun., 2017.

ALMEIDA, Jéssica de. Quando dois somos muitos: histórias de vida dialogadas e a atuação do professor de música na escola básica. 2016, 98p. Dissertação (Mestrado em Educação) - Universidade Federal de Santa Maria, Programa de Pós-Graduação em Educação, Santa Maria, 2016.

ALVES, Gislene A. Pesquisa biográfica em educação musical: narrativas e (auto)biografias como abordagem de pesquisa da formação e atuação de professores de música. XVI ENCONTRO REGIONAL SUL DA ABEM. EDUCAÇÃO MUSICAL: FORMAÇÃO HUMANA, ÉTICA E PRODUÇÃO DE CONHECIMENTO, XVI, Blumenau, 11 a 13 de setembro de 2014.

Anais... (on line) XVI Encontro Regional Sul da Associação Brasileira de Educação Musical - ABEM, 2014.

BECALLI, Fernanda Zanetti; SCHWARTZ, Cleonara, Maria. A hora e a vez dos cadernos escolares como fontes históricas de pesquisa sobre práticas alfabetizadoras. Revista Linhas. Florianópolis, v. 18, n. 38, p183- 213, set./dez. 2017. DOI: $10.5965 / 1984723818382017183$.

BELLOCHIO, Claudia. Educação musical e unidocência: pesquisas, narrativas e modos de ser do professor de referência. Porto Alegre: Sulina, 2017.

BERLINER, D. C. A personal response to those who bash teacher education. Journal of Teacher Education, v. 51, n. 5, p. 358-371, 2000. DOI: $10.1177 / 0022487100051005004$.

BLOOM, Benjamim S. Taxonomy of educational objectives: português taxionomia de objetivos educacionais. Porto Alegre: Globo, 1972. 2 v.

DALLABRIDA, lara Calladore. Sentidos da Educação Musical na formação acadêmicoprofissional do pedagogo. 2015, 155p. Dissertação (Mestrado em Educação) -

Universidade Federal de Santa Maria, Programa de Pós-Graduação em Educação, Santa Maria, 2015.

DELORY-MOMBERGER, Christine. Motivos e espaços de pesquisa. Ensaio de uma biografia de pesquisadora. In. ABRAHÃO, Maria Helena M.B. A aventura (auto)biográfica. Tomo II. Porto Alegre: EDIPUCRS, 2018. p. 39-55.

DOURADO, Solange. A educação musical nas narrativas de licenciandas de pedagogia: vivencias e ausências. 2013, 111p. Dissertação (Mestrado em Educação) - Universidade Federal do Mato Grosso, Programa de Pós-Graduação em Educação., Rondonópolis, 2013. 
FERRAROTTI, Franco. Sobre a ciência da incerteza: o método biográfico na investigação em ciências sociais. Ramada, Portugal e Luanda, Angola: Edições Pedagogo e Edições Mulemba, 2013.

FERRAROTTI, Franco. Histórias de vida: o método biográfico nas Ciências Sociais. Natal: EDUFRN, 2014.

FIGUEIROA, A; ABREU, D. Histórias de vida de professores de música de escolas de educação básica. Construindo o interesse pelo tema de pesquisa. In: CONGRESSO INTERNACIONAL DE PESQUISA (AUTO)BIOGRÁFICA, CIPA, VII, Cuiabá, 17 a 20 de jul., Anais... Cuiabá: UFMT, 2016. Tema do evento: Narrativas autobiográficas: conhecimentos, experiências e sentidos.

FREIRE, Paulo. Professora sim, tia, não: cartas a quem ousa ensinar. São Paulo: Editora Olho D’água, 1999.

GAINZA, Violeta. Fundamentos, materiales y tecnicas de la educación musical. Buenos Aires, 1977.

GAULKE, Tamar G. O desenvolvimento profissional de professores de música da educação básica: um estudo a partir de narrativas autobiográficas. 2013, 228p. Tese (Doutorado em Música) - Universidade Federal do Rio Grande do Sul, Programa de PósGraduação em Música, Porto Alegre, 2013.

GRAETZER, G.; YEPES, A. Introducción a la practica del Orff-Schulwerk. Metodo Orff. $5^{\text {a }}$ ed. Buenos Aires: Barry Editorial, 1961.

JOLY, Ilza Z. A história de vida de uma professora de música como elemento formador de novos educadores musicais. Fundamentos da Educação Musical. Salvador, n. 4. p. 290298, out. 1998.

LAPIERRE. A; AUCOUTURIER, B. A simbologia do movimento: psicomotricidade e educação, Porto Alegre, ARTMED, 1986.

LIMA, Janaína Machado A. Higenburg Hasenack: memórias de uma educadora musical. 2013, 188p. Dissertação (Mestrado em Educação) - Universidade Federal de Santa Maria, Santa Maria, Programa de Pós-Graduação em Educação, Santa Maria, 2013.

LOURO, Ana Lucia de M. Ser docente universitário-professor de música: dialogando sobre identidades profissionais com professores de instrumento. 2004, 195p. Tese (Doutorado em Música) - Universidade Federal do Rio Grande do Sul, Programa de PósGraduação em Música, Porto Alegre, 2004.

LOURO, A. L.; TEIXEIRA, Z. L.; RAPÔSO, M. (Orgs.) Aulas de música: narrativas de professores numa perspectiva (auto)biográfica, Curitiba: Editora CDV, 2014. 
LOURENÇO, Eliane. O ensino de História encontra seu passado: memórias da atuação docente durante a ditadura civil-militar. Revista Brasileira de História, v. 30, n. 60. p. 97120, 2010.

MAFFIOLETTI, Leda de A.; ABRAHÃO, Maria Helena M. B. Conhecimentos produzidos a partir da Pesquisa Narrativa em Educação Musical. In: CONGRESSO IBERO-AMERICANO EM INVESTIGAÇÃO QUALITATIVA (CIAIQ2017) E DO 2ND INTERNATIONAL SYMPOSIUM ON QUALITATIVE RESEARCH (ISQR2017), 6², Salamanca, 2017. Atas. Salamanca, 2017. v.1, p. 920-929.Tema do evento: a prática na Investigação Qualitativa: exemplo de estudos.

MAFFIOLETTI, Leda. Pensar e pena sobre si mesmo. In: ABRAHÃO, Maria Helena, M.B. (Org.) A nova aventura (auto)biográfica, Tomo II. Porto Alegre: EDIPUCRS, 2018. p. 183206.

MARCELO GARCIA, Carlos. La profesión docente en momentos de cambios. ¿Qué nos dicen los estudios internacionales? CEE Participación Educativa, n. 16, p. 49-68, mar., 2011.

MIGNOT, Ana C. V. CUNHA, Maria Teresa, S.; Razões para guardar: a escrita ordinária em arquivos de professores. Revista Educação em questão, Natal, v.25, n.11, p. 40-61, jan/abr. 2006.

PASSEGGI, M. C. Narrar é humano! Autobiografar é um processo civilizatório. In: PASSEGGI, M.C; SILVA, Vivian (Orgs) Invenções de vidas, compreensão de itinerários e alternativas de FORMAÇÃO. São Paulo: Cultura acadêmica, 2010. p. 103-130.

PINEAU, Gaston: Le GRAND, Jean-Louis. As histórias de vida. Trad. Carlos Eduardo G. Braga e Maria Conceição Passeggi. Natal, EDUFRN, 2012.

RICOEUR, Paul. Tempo e narrativa: concordância/Discordância. Trad. João Batista Botton. Kriterion, Belo Horizonte, v. 53 n. 125, p. 299-310, Jun., 2012.

RICOEUR, Paul. Tempo e Narrativa. Tomo III. Trad. Paulo Leal Pereira. São Paulo: Papirus, 1997.

RICOEUR, Paul. Tempo e Narrativa. Tomo I. Trad. Constança Marcondes Cesar. São Paulo: Papirus, 1994.

RICOEUR, Paul. O si-mesmo como um outro. São Paulo: Papirus, 1991.

SERAFINE, Mary Louise. Cognitive processes in music: discoveries vs definitions. Bulletin of council for research in music education, 73, p. 1-14, 1983.

SERÓDIO, Liana A. A música, a narrativa e a formação de professores. 2007, 161p. Dissertação (Mestrado) - Pontifícia Universidade Católica de Campinas, Centro de Ciências Sociais Aplicadas, Programa de Pós-Graduação em Educação da Área de Ensino Superior, Campinas, 2007. 
SOARES, Magda. Metamemória-memórias: travessia de uma educadora. $2^{\mathrm{a}}$ ed. São Paulo: Cortez, 2001.

SOUZA, Jusamara. Sobre as várias histórias da educação musical no Brasil. Revista da ABEM, Londrina, v. 22, n. 33, p. 109-120, jul./dez., 2014.

SOUZA, Zelmielen A. Aproximações e distanciamentos na docência virtual em música: narrativas de professores formadores em cursos de pedagogia da UAB. 2018, 301p. Tese (Doutorado em Educação) - Universidade Federal de Santa Maria, Programa de PósGraduação em Educação, Santa Maria, 2018.

STOKOE, Patricia. La expresion corporal y el niño. Buenos Aires: Ricordi Americana, 1967. TORRES, Maria Cecília. Músicas do cotidiano e memórias musicais: narrativas de si de professores do ensino fundamental. In: SOUZA, Jusamara (Org.). Aprender e ensinar música no cotidiano. Porto Alegre: Sulina, 2008.

VIEIRA, Karina Firmino. Ser professor de música de projeto social: um estudo com entrevistas narrativas (auto)biográficas. 2017, 144p. Dissertação (Mestrado em Música) Universidade de Brasília, Programa de Pós-Graduação Música e Contexto. Instituto de Artes, Brasília, 2017.

WEBER, Vanessa. Tornando-se professor de instrumento: Narrativas de docentesbacheréis. 2014, 145p. Tese (Doutorado em Educação) Universidade Federal de Santa Maria, Santa Maria, Programa de Pós-Graduação em Educação, Santa Maria, 2014.

WILLEMS, E. Las bases psicológicas de la educación musical. Buenos Aires: Eudeba, 1961.

Recebido em: 24/10/2018 Aprovado em: 09/12/2018

Universidade do Estado de Santa Catarina - UDESC Programa de Pós-Graduação em Educação - PPGE Revista Linhas

Volume 20 - Número 42 - Ano 2019 revistalinhas@gmail.com 